\title{
AS CORES DA CIDADE: ESTUDO DOS CONTRASTES CROMÁTICOS NOS ELEMENTOS DO MOBILIÁRIO URBANO COMO AUXÍLIO À ORIENTABILIDADE DE PESSOAS COM BAIXA VISÃO.
}

\author{
PADOAM, Flavia Cunha (1); \\ BERNARDI, Núbia (2) \\ (1) Universidade Estadual de Campinas, Graduanda em Engenharia Civil. \\ e-mail: flaviapadoam@gmail.com \\ (2) Universidade Estadual de Campinas, Professora Doutora, Faculdade de Engenharia \\ Civil, Arquitetura e Urbanismo. \\ e-mail: nubiab@fec.unicamp.br
}

\begin{abstract}
RESUMO
Em um meio planejado para a mobilidade de pessoas sem deficiências, é um desafio desenvolver instrumentos que facilitem a locomoção independente e sem riscos para os deficientes visuais na cidade. Este trabalho analisa uma proposta que pode facilitar a orientabilidade de pessoas com baixa visão: a aplicação de cores em elementos arquitetônicos gerando contrastes cromáticos que os evidenciem. Com a aplicação de um teste de percepção cromática junto a pessoas com baixa visão, foi analisada a eficiência do uso das cores em elementos do mobiliário urbano, obtendo resultados promissores e indicando a necessidade de continuação desses estudos.
\end{abstract}

Palavras chave: baixa visão; contrastes cromáticos; orientabilildade.

\begin{abstract}
In an environment planned for the mobility of people without disabilities, it's challenging to develop devices that facilitate the independent and riskless locomotion of the visually impaired in the city. This paper analyses a proposal that can improve the orientability of people with partial or low vision: the application of colors on architectonic elements creating chromatic contrasts that put them in evidence. With the application of a chromatic perception test with the visually impaired with partial vision, the efficiency of colors on urban elements was analysed, obtaining promissing results and indicating the need of continuation for these studies.
\end{abstract}

Keywords: partial/low vision; chromatic contrasts; orientability.

\section{INTRODUÇÃO}

Garantir a mobilidade eficiente, segura e independente de todas as pessoas com deficiência através de soluções de acessibilidade é um desafio urgente a ser explorado. Acessibilidade espacial não significa somente chegar ao lugar desejado, mas engloba também a necessidade de o usuário compreender a função, a organização e as relações espaciais do local, e participar das atividades que ali ocorrem. Assim, entende-se acessibilidade como um processo gerador de liberdade individual através da informação, mobilidade e participação: 


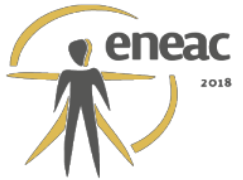

as pessoas devem poder vivenciar o ambiente construído de forma plena e completa, sendo integradas à sociedade através da participação nas atividades. Todas essas ações devem ser realizadas com segurança, conforto e independência (BINS ELY, DISCHINGER , PIARDI; 2012).

A maioria dos edifícios nas cidades foi construída sem considerar questões de acessibilidade espacial, oferecendo assim barreiras para as pessoas com deficiência. No entanto, não somente os edifícios apresentam barreiras, mas também o mobiliário urbano, que engloba todos os objetos, elementos e pequenas construções, de natureza utilitária ou não, que integram a paisagem urbana, implantados mediante autorização do poder público, em espaços públicos e privados (NBR 9283/1986).

Segundo o Censo 2010 do IBGE (2012), 18,6\% da população brasileira declararam ter deficiência visual, sendo esta a maior incidência dentre todos os tipos de deficiência visual, auditiva, motora, mental e intelectual (CENSO 2010, 2012). A separação entre deficientes visuais com cegueira e pessoas com visão subnormal se dá por duas escalas oftalmológicas: acuidade visual (aquilo que se enxerga a determinada distância) e campo visual (amplitude da área alcançada pela visão) (NISHIMORI, 2013).

A visão subnormal ou baixa visão é dada por um grau de enfraquecimento visual que diminui a capacidade funcional e o desempenho da visão. As causas podem ser congênitas (quando o indivíduo nasce com essas características, como catarata congênita, glaucoma congênito) ou adquiridas (por acidentes ou doenças ao longo da vida, como diabetes, descolamento da retina, glaucoma, catarata, degeneração macular, entre outros) (CARVALHO, 2002).

Essas diferentes causas acometem estruturas distintas do sistema visual, levando ao comprometimento de funções variadas e dando origem a diminuição de acuidade e campo visual; ofuscamento; incapacidade de distinção de cores; dificuldade de adaptação à luz e ao escuro; dificuldade para orientar-se e deslocar-se espacialmente; difícil distinção de contornos pela ausência de visão periférica; falta de foco ocular, não reconhecendo faces, por exemplo (por ausência de nitidez); impossibilidade de ler sem auxílio de instrumentos, pela falta de visão central etc (VARELLA, 2012).

No âmbito da deficiência visual, é comum que a acessibilidade seja voltada para indivíduos com cegueira total. No entanto, é importante difundir o conhecimento sobre as diferentes deficiências e como pessoas com baixa visão podem atuar na sociedade, fazendo uso de sua visão residual nas atividades diárias, inclusive para locomoção. Neste ponto surge a alternativa de uso de cores contrastantes no mobiliário urbano e também no interior de edificações para auxiliar na mobilidade e orientabilidade de pessoas com baixa visão.

Segundo a NBR9050 (2015), o contraste visual tem como função destacar elementos entre si por meio das composições claro-escuro ou escuro-claro para chamar a atenção do observador, e também deve ser usado como informação visual e para alertar perigos. $O$ papel da cor nos sistemas informacionais é de organizar e atribuir significado à informação, e ainda, contribuir para o conforto visual e o bem-estar do usuário (GUIMARÃES, 2000).

A cor deve agir junto da rede de sistemas informacionais do ambiente construído, de forma que as características arquitetônicas, o layout, o mobiliário, os equipamentos, os objetos decorativos e a sinalização tenham o mesmo potencial para a informação visual, sendo passíveis de auxiliar os usuários em suas locomoções (MONT'ALVÃO, RANGEL; 2014).

A tese de doutorado de Gamito (2012) tem uma base similar ao estudo proposto neste trabalho, fazendo um profundo estudo sobre a cor no mobiliário urbano de alguns bairros de Lisboa. Foi feito um levantamento das cores presentes em diversos bairros através de registros fotográficos para avaliar a aplicação cromática existente em cada um deles. Em seguida, respeitando a história e o papel de cada bairro dentro da cidade, foram criados planos cromáticos que contribuíssem para aumentar a visibilidade dos elementos do 


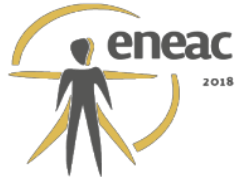

mobiliário urbano, facilitando a orientação dentro da cidade. Finalizando, foi feita uma simulação digital aplicando o plano cromático nas imagens obtidas (GAMITO, 2012).

Da mesma forma, este trabalho analisa a aplicação de contrastes cromáticos em elementos do meio urbano que configuram barreiras para a mobilidade de pessoas com baixa visão, visando criar uma alternativa de auxílio à orientabilidade através da percepção melhorada dos elementos, evitando acidentes e conferindo autonomia às pessoas com visão subnormal.

O desenvolvimento deste trabalho traz à realidade a aplicação dos conceitos estudados ao avaliar como está hoje a acessibilidade em alguns espaços físicos dentro da Universidade Estadual de Campinas, relacionando barreiras físicas, contrastes cromáticos e mobilidade, para assim estudar como os contrastes de cores podem ser aplicados no cotidiano das pessoas com baixa visão para melhorar sua orientabilidade e mobilidade na cidade.

\section{METODOLOGIA}

Este trabalho utilizou um estudo de caso para avaliar, através de um teste de percepção cromática, a eficácia da aplicação de cores em elementos arquitetônicos presentes em locais que apresentam risco para a mobilidade de pessoas com deficiência visual, visando também compreender quais cores são mais perceptíveis para pessoas com baixa visão.

A pesquisa teve duas etapas: uma inicial, exploratória, para compreender 0 ambiente urbano selecionado para o estudo de caso e uma segunda etapa participativa, através da aplicação de uma dinâmica com pessoas com baixa visão.

Na primeira etapa foi realizado um percurso dentro da Universidade Estadual de Campinas, passando por locais muito frequentados pelos usuários do campus, ao longo do qual foram feitos registros fotográficos de locais que apresentam barreiras físicas e pouco contraste cromático entre os elementos arquitetônicos, podendo dificultar a mobilidade e orientabilidade de pessoas com baixa visão no percurso.

Destes registros fotográficos foram selecionadas 06 imagens que representassem bem 0 percurso com suas falhas de mobilidade e obstáculos sem contrastes cromáticos com o entorno. Em seguida, estas seis imagens foram manipuladas digitalmente através do software Photoshop CC, que possibilitou a alteração da cor de alguns elementos importantes do caminho, como postes, jardineiras, bancos, lixeiras, escadas: elementos que antes tinham cores pouco contrastantes com o meio em que estão inseridos, sendo assim difíceis de serem reconhecidos e prejudicando a mobilidade de pessoas com baixa visão. Foram aplicadas cores que oferecem grande contraste com o meio circundante, fazendo com que tais elementos fiquem em destaque. De cada imagem original resultaram 3 (três) imagens manipuladas.

Na segunda etapa da pesquisa foi realizada uma dinâmica na qual pessoas com baixa visão visualizaram em formato digital as imagens selecionadas, através de uma tela de notebook, para avaliar a eficácia da implementação dos contrastes cromáticos com a simulação digital. A dinâmica foi aplicada a 7 (sete) pessoas com baixa visão que são frequentadoras do Centro Cultural Louis Braille de Campinas (CCLB). A atividade foi autorizada pelo presidente da instituição e pelo Comitê de Ética em Pesquisa (CEP), sendo que todos os participantes tiveram acesso ao Termo de Consentimento Livre e Esclarecido (TCLE) exigido pelo CEP.

Para a realização da dinâmica, as imagens foram divididas em seis blocos, cada um referente a uma imagem original (Bloco 1: saída do IFGW, correspondente à imagem 1 original e 3 imagens manipuladas; Bloco 2: escadas do Ciclo Básico 1, correspondente à imagem 2 original e 3 imagens manipuladas; e assim por diante). Para cada bloco, inicialmente o participante visualiza somente a imagem original, e responde se observa 


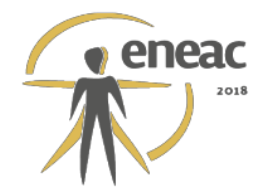

barreiras no ambiente que possam prejudicar sua locomoção (se sim, quais) e se a uniformidade das cores também prejudicaria sua locomoção. Em seguida, o participante visualiza uma das imagens manipuladas digitalmente ao lado da imagem original, e responde se percebe diferenças entre as duas (se sim, quais), se houve melhora e se as modificações poderiam ajudar em sua locomoção. Por fim, pergunta-se o que o participante achou da escolha das cores, se trocaria por outras. Subsequentemente, compara-se cada imagem manipulada à original, apresentadas lado a lado, repetindo as perguntas da entrevista. O procedimento é repetido três vezes para cada um dos seis blocos, já que são três imagens manipuladas para cada uma das seis originais.

\section{DESENVOLVIMENTO}

O percurso escolhido liga o Instituto de Física Gleb Wataghin (IFGW) à Biblioteca Central Cesar Lattes, um caminho comum aos alunos e trabalhadores da UNICAMP, realizado todos os dias por centenas de pessoas. Sendo localizado no centro do campus, cruza locais de grande movimentação: os Ciclos Básicos 1 e 2, nos quais alunos de todos os institutos têm aulas; a Praça Central, que é caminho diário de todos que vão ao Restaurante Universitário, local de almoço dos estudantes e trabalhadores da Universidade e à Biblioteca Central, a maior do campus, que reúne o material de diversos cursos, portanto muito procurada. $O$ percurso foi realizado no período da manhã do dia 4/11/2016, entre 8:00 e 9:00h, e no período da tarde do dia 16/12/2016, entre as 15:00 e 16:00h.

A Tabela 1 apresenta os seis registros fotográficos selecionados ao longo do percurso, com um diagnóstico acerca da mobilidade que o local oferece, as barreiras físicas encontradas e a situação cromática existente.

Quadro 1 - Imagens e características do percurso analisado.

\begin{tabular}{|c|c|c|c|}
\hline Imagem & Mobilidade & Barreiras & Cores \\
\hline 1: Saída do IFGW & $\begin{array}{l}\text { - moderada; } \\
\text { - tem piso tátil; } \\
\text { - falta } \\
\text { identificação do } \\
\text { caminho aos } \\
\text { bancos. }\end{array}$ & $\begin{array}{l}\text { - postes; } \\
\text { - jardineiras; } \\
\text { - árvores; } \\
\text { - bancos; } \\
\text { - pergolado } \\
\text { de madeira; }\end{array}$ & $\begin{array}{l}\text { - piso tátil com cores desbotadas, } \\
\text { não contrastante com o piso do } \\
\text { entorno; } \\
\text { - jardineiras e bancos de cor cinza } \\
\text { pouco contrastante com o entorno; } \\
\text { - Ponto positivo: faixa vermelha no } \\
\text { entorno das jardineiras, porém } \\
\text { desbotadas. }\end{array}$ \\
\hline $\begin{array}{l}\text { 2: Escadas que } \\
\text { levam ao Ciclo } \\
\text { Básico } 1\end{array}$ & $\begin{array}{l}\text { - reduzida; } \\
\text { - sem piso tátil; } \\
\text { - dificultada pela } \\
\text { presença da } \\
\text { escada. }\end{array}$ & $\begin{array}{l}\text { - escada; } \\
\text { - poste; } \\
\text { - pilares. }\end{array}$ & $\begin{array}{c}\text { - todos os elementos têm cores } \\
\text { em tons de bege, com contraste } \\
\text { quase nulo; } \\
\text { - escada sem destaque, sem faixa } \\
\text { de cor contrastante que delimite } \\
\text { os degraus. }\end{array}$ \\
\hline
\end{tabular}




\begin{tabular}{|c|c|c|c|}
\hline $\begin{array}{l}\text { 3: Acesso no Ciclo } \\
\text { Básico } 1\end{array}$ & $\begin{array}{l}\text { - auxiliada pela } \\
\text { presença das } \\
\text { muretas que } \\
\text { separam os } \\
\text { possíveis } \\
\text { caminhos; } \\
\text { - sem piso tátil. }\end{array}$ & $\begin{array}{l}\text { - muretas; } \\
\text { - bancos. }\end{array}$ & $\begin{array}{c}\text { - as muretas tem mesma } \\
\text { tonalidade que o piso, dificultando } \\
\text { a escolha do caminho. }\end{array}$ \\
\hline $\begin{array}{c}\text { 4: Saída do Ciclo } \\
\text { Básico } 1\end{array}$ & $\begin{array}{c}\text { - facilitada pelo } \\
\text { contraste entre } \\
\text { grama e piso; } \\
\text { - lixeiras } \\
\text { escondidas atrás } \\
\text { do poste, tendo } \\
\text { acesso } \\
\text { prejudicado; } \\
\text { - nenhuma } \\
\text { orientação para } \\
\text { chegada à } \\
\text { edificação; } \\
\text { - sem piso tátil. }\end{array}$ & $\begin{array}{c}\text { - lixeiras; } \\
\text { - postes; } \\
\text { - placas de } \\
\text { informações; } \\
\text { - guia } \\
\text { levantada } \\
\text { para grama. }\end{array}$ & $\begin{array}{l}\text { - placas de informação: pretas } \\
\text { com letras muito pequenas, de um } \\
\text { branco desbotado, difícil } \\
\text { legibilidade; } \\
\text { - lixeiras de cor desbotada, difícil } \\
\text { identificação; } \\
\text { - guias que separam a grama tem } \\
\text { cor idêntica ao piso, dificultando } \\
\text { sua percepção. }\end{array}$ \\
\hline $\begin{array}{l}\text { 5: Elementos na } \\
\text { Praça Central }\end{array}$ & $\begin{array}{l}\text { - sem piso tátil; } \\
\text { - sem jardineira } \\
\text { envolvendo a } \\
\text { base de diversas } \\
\text { árvores; } \\
\text { - vão livre sem } \\
\text { elementos que } \\
\text { proporcionem } \\
\text { orientabilidade. }\end{array}$ & $\begin{array}{l}\text { - bancos; } \\
\text { - árvores; } \\
\text { - postes; } \\
\text { - guias } \\
\text { levantadas } \\
\text { separando } \\
\text { piso e terra; } \\
\text { - tampa de } \\
\text { concreto. }\end{array}$ & $\begin{array}{l}\text { - o tom do piso é muito similar à } \\
\text { terra, dificultando a percepção da } \\
\text { mudança; } \\
\text { - cor da tampa de concreto e da } \\
\text { guia levantada as tornam } \\
\text { imperceptíveis em relação ao piso; } \\
\text { - bancos e jardineiras de cor } \\
\text { pouco contrastante com o piso. }\end{array}$ \\
\hline $\begin{array}{l}\text { 6: Acessos ao } \\
\text { primeiro andar do } \\
\text { Ciclo Básico } 2\end{array}$ & $\begin{array}{l}\text { - sem piso tátil; } \\
\text { - sem orientação } \\
\text { para a presença } \\
\text { da escada e da } \\
\text { rampa; } \\
\quad \text { - placa de } \\
\text { informação com } \\
\quad \text { letras muito } \\
\quad \text { pequenas. }\end{array}$ & - escadas; & $\begin{array}{l}\text { - o desenho geométrico formado } \\
\text { pelas cores da escada é apenas } \\
\text { estético, cria uma "linha" diagonal } \\
\text { que pode dificultar o deslocamento } \\
\text { do usuário; } \\
\text { - faltam faixas de cor contrastante } \\
\text { para delimitar os degraus; } \\
\text { - placas de informação: letras } \\
\text { brancas e fundo preto criam bom } \\
\text { contraste, no entanto as cores } \\
\text { estão desbotadas. }\end{array}$ \\
\hline
\end{tabular}

Fonte: elaborado pelos autores.

O percurso é majoritariamente composto por tons de marrom, bege, cinza e vermelho, todos desbotados e que não oferecem contraste entre si. Dessa forma, as cores não auxiliam na orientação do caminho das pessoas com baixa visão, que precisam buscar outras formas de se guiar, como auxílio de terceiros, bengalas, lentes de correção quando possível. 


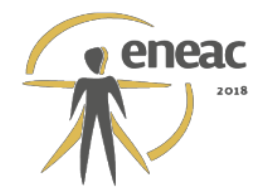

Com a simulação cromática através do software Photoshop CC, cada imagem foi manipulada três vezes, destacando separadamente diferentes grupos de elementos dos ambientes. O primeiro grupo representa a inserção de piso tátil onde não havia e intensificação da cor dos já existentes. $\mathrm{Na}$ maioria das imagens o segundo grupo corresponde aos equipamentos de iluminação, que configuram barreiras físicas bastante imperceptíveis quando não têm cor contrastante com o meio, já que são elementos pouco espessos. O terceiro caso, que ocorre em todas as imagens, é a modificação da cor dos mobiliários que configuram barreiras maiores à mobilidade, como bancos e jardineiras. Também foram manipuladas as cores de elementos das escadas e rampa (corrimão, degraus), colocando piso tátil de alerta. Por fim, também há imagens com mudança cromática nas placas informativas.

\section{RESULTADOS}

A Tabela 2 mostra a imagem original seguida das três imagens manipuladas para cada local selecionado e os resultados da entrevista aplicada na dinâmica, além de observações particulares dos participantes. Foi feita uma análise compilando as respostas dos participantes imagem a imagem, cumprindo a finalidade de avaliar a efetividade do uso de cores em cada elemento.

\section{Quadro 2 - Imagens com manipulação de cores e resultados da dinâmica.}

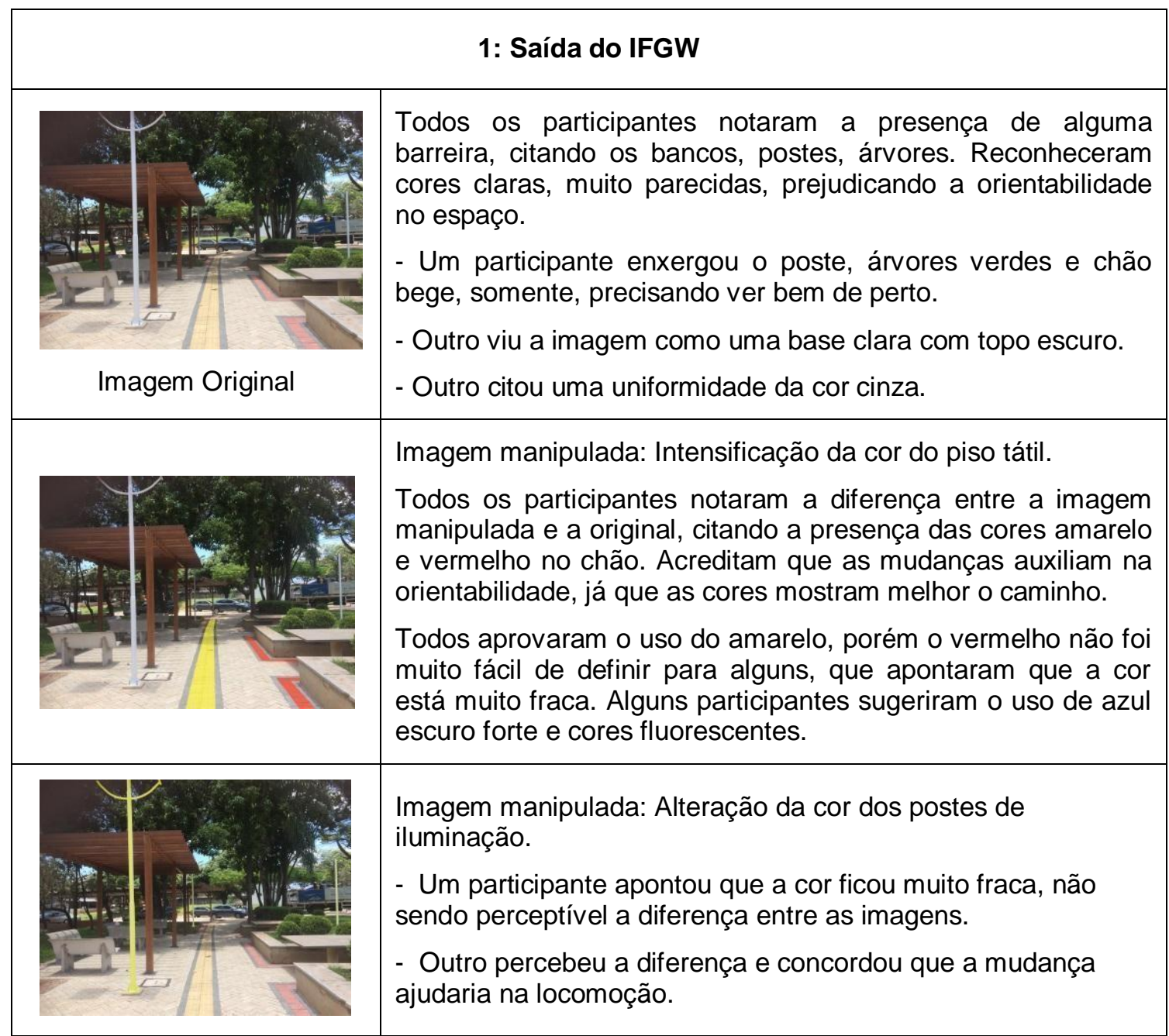




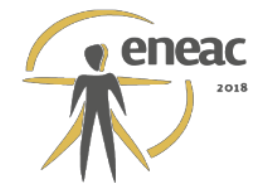

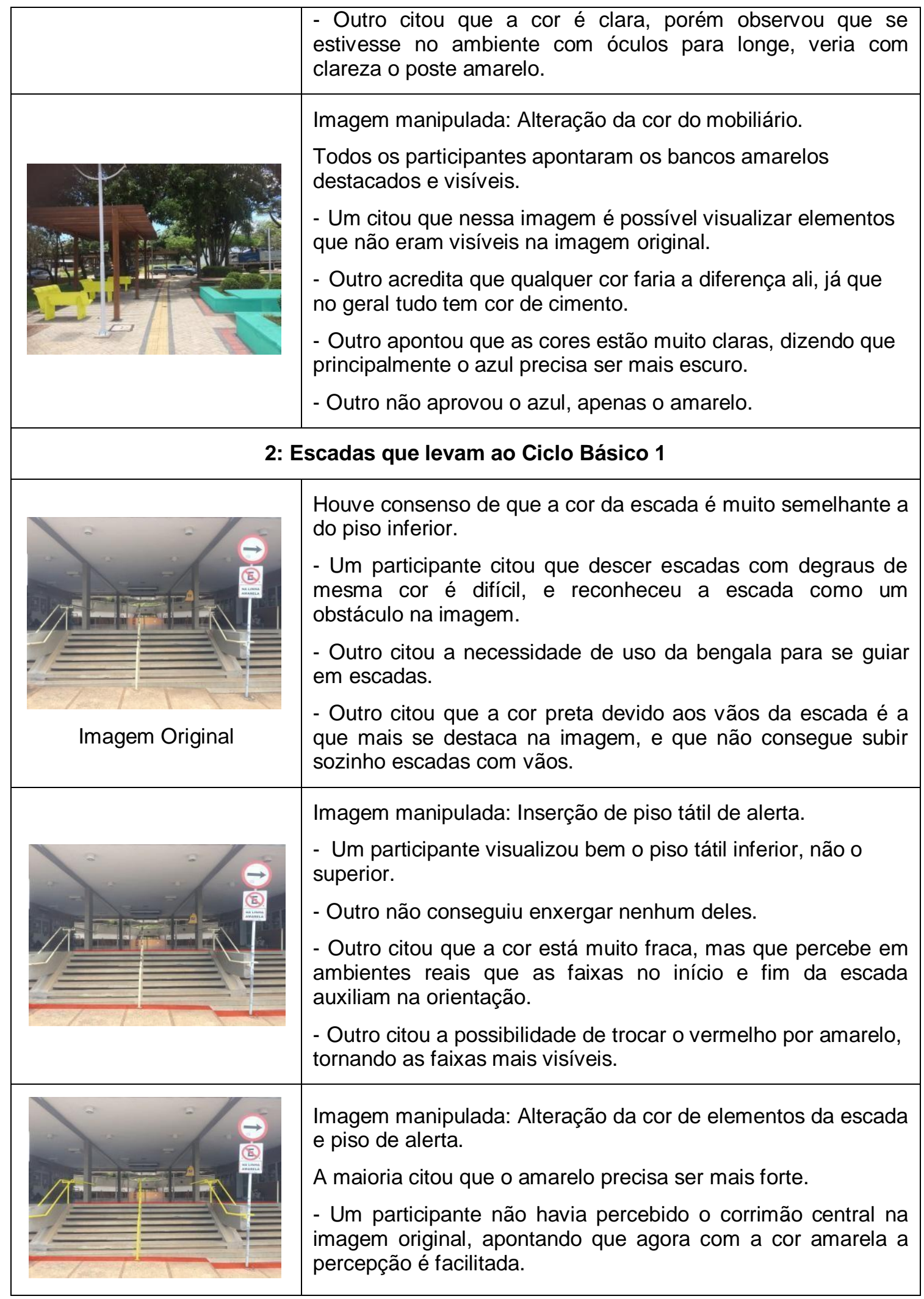




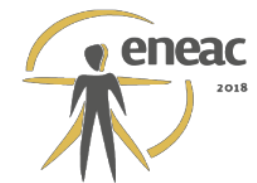

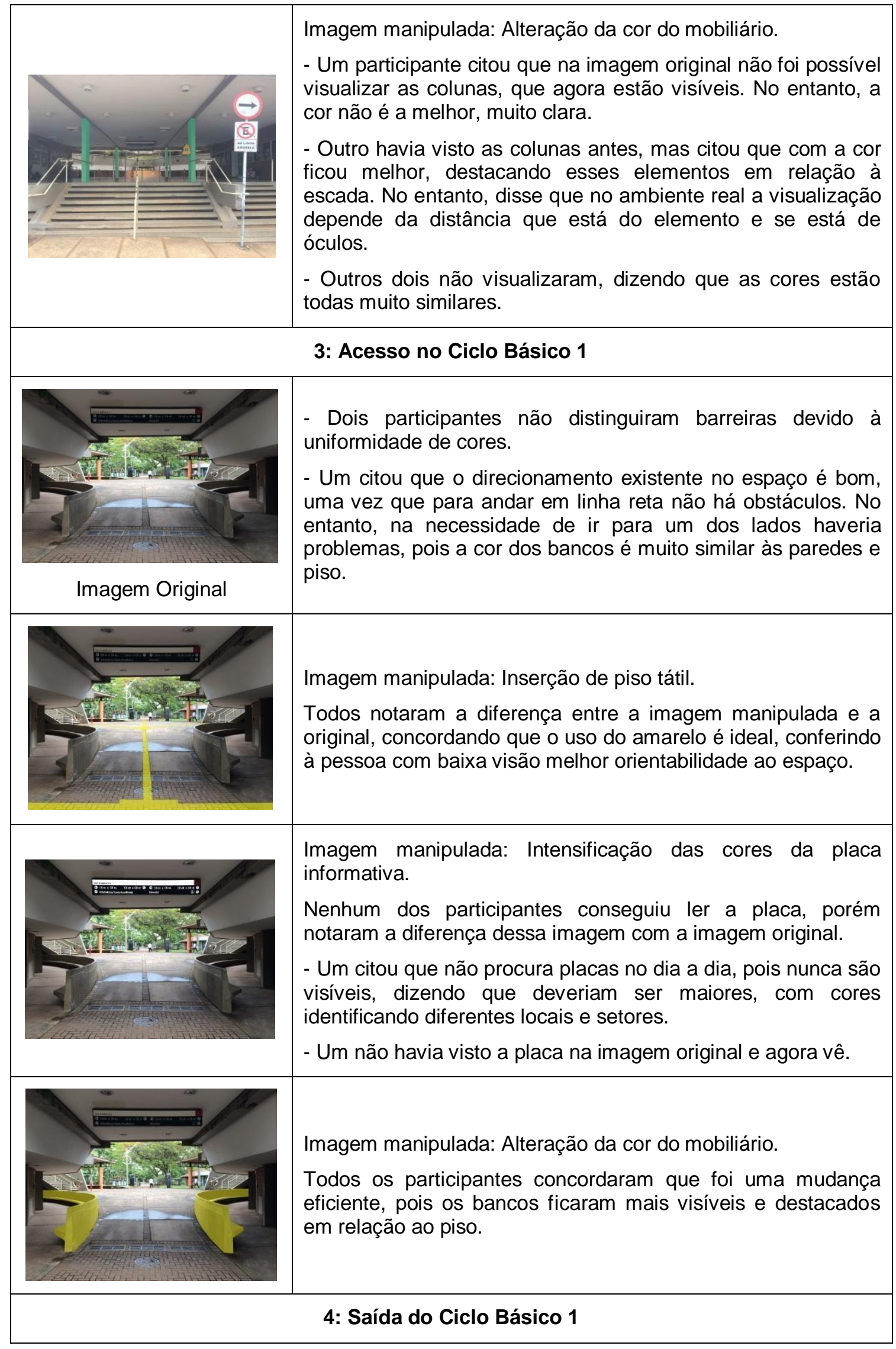




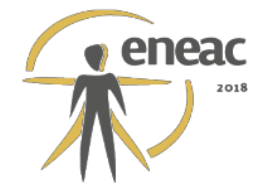

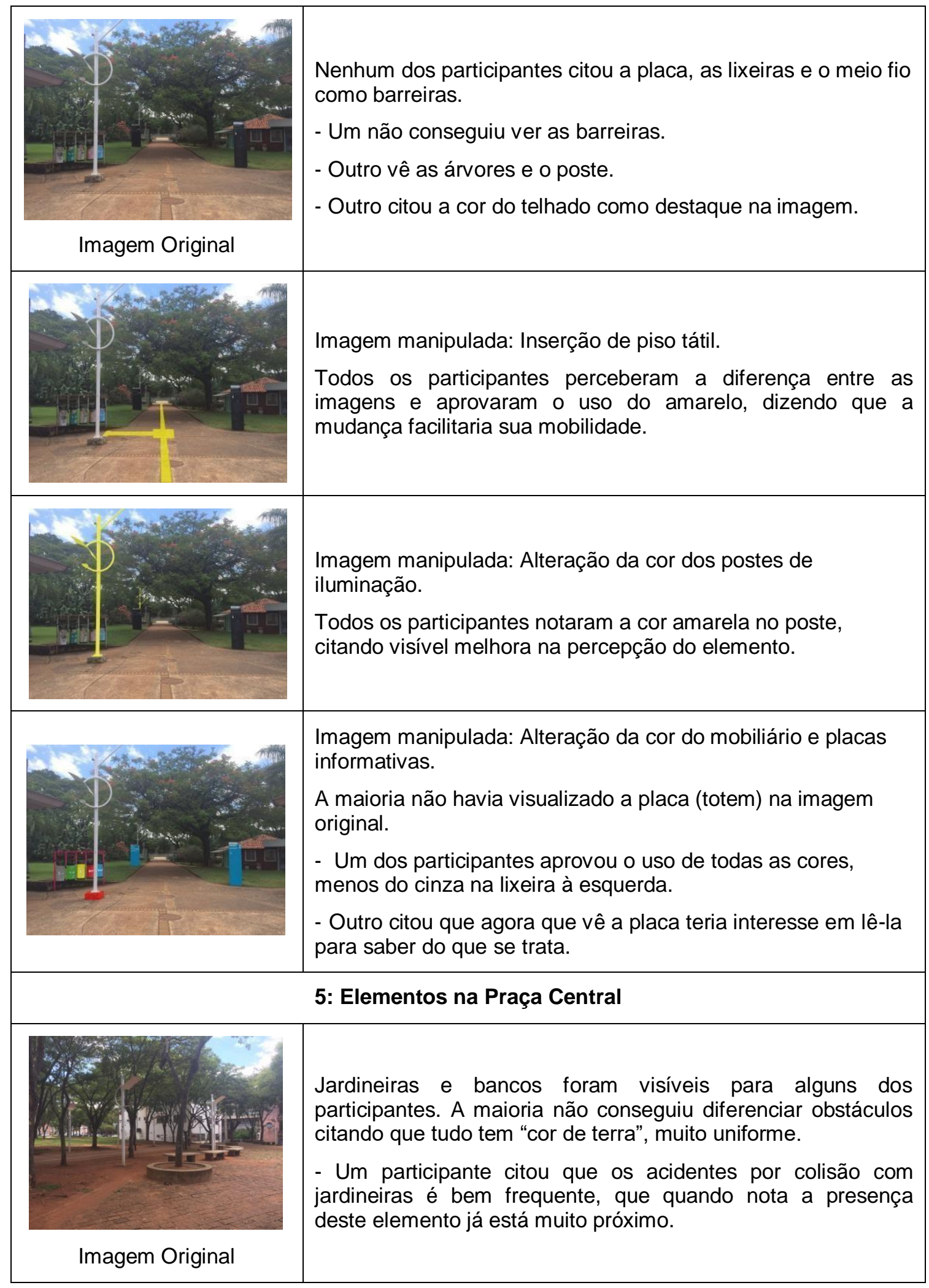




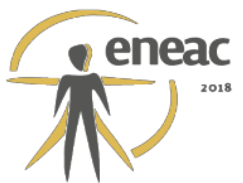

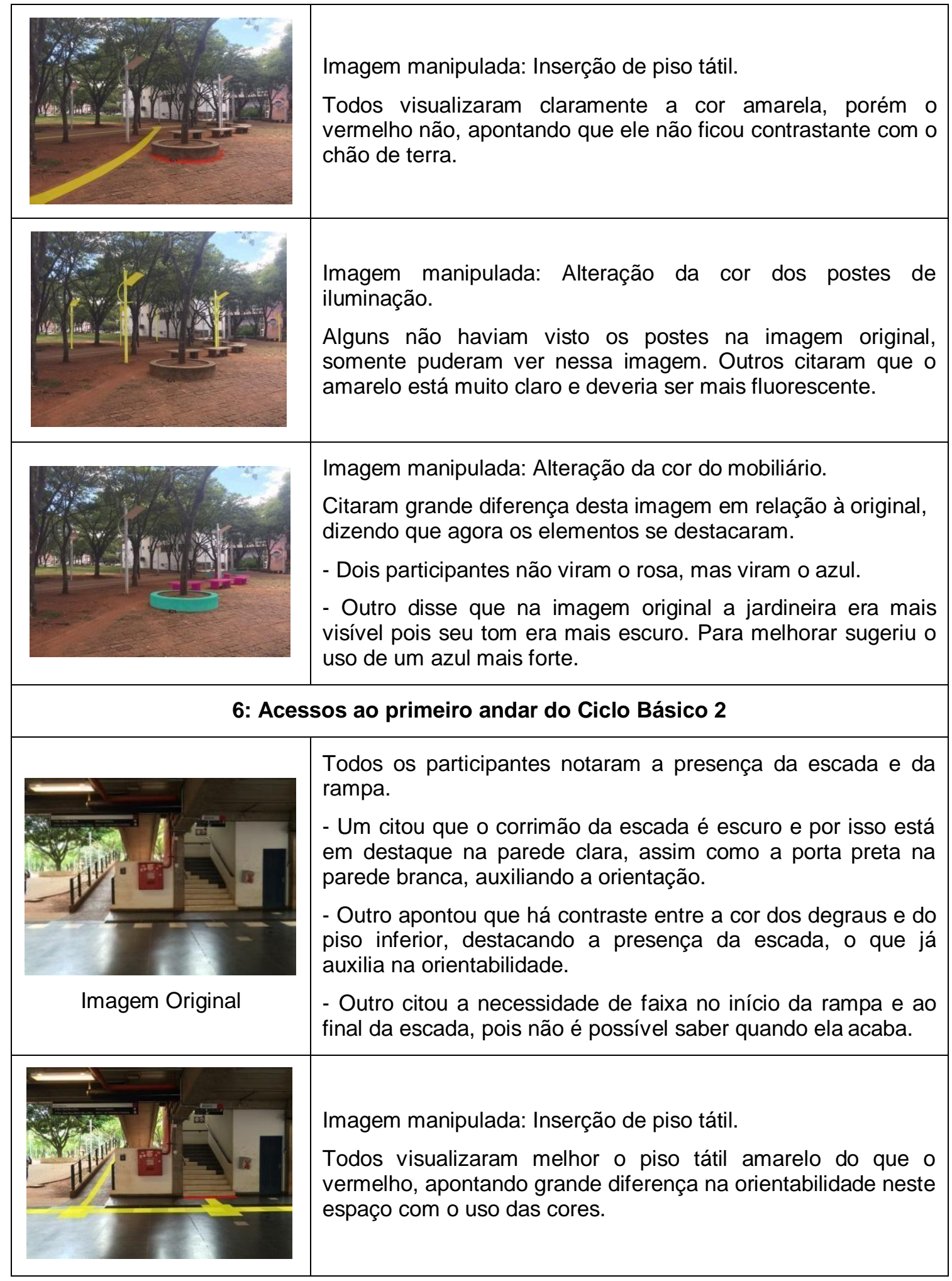



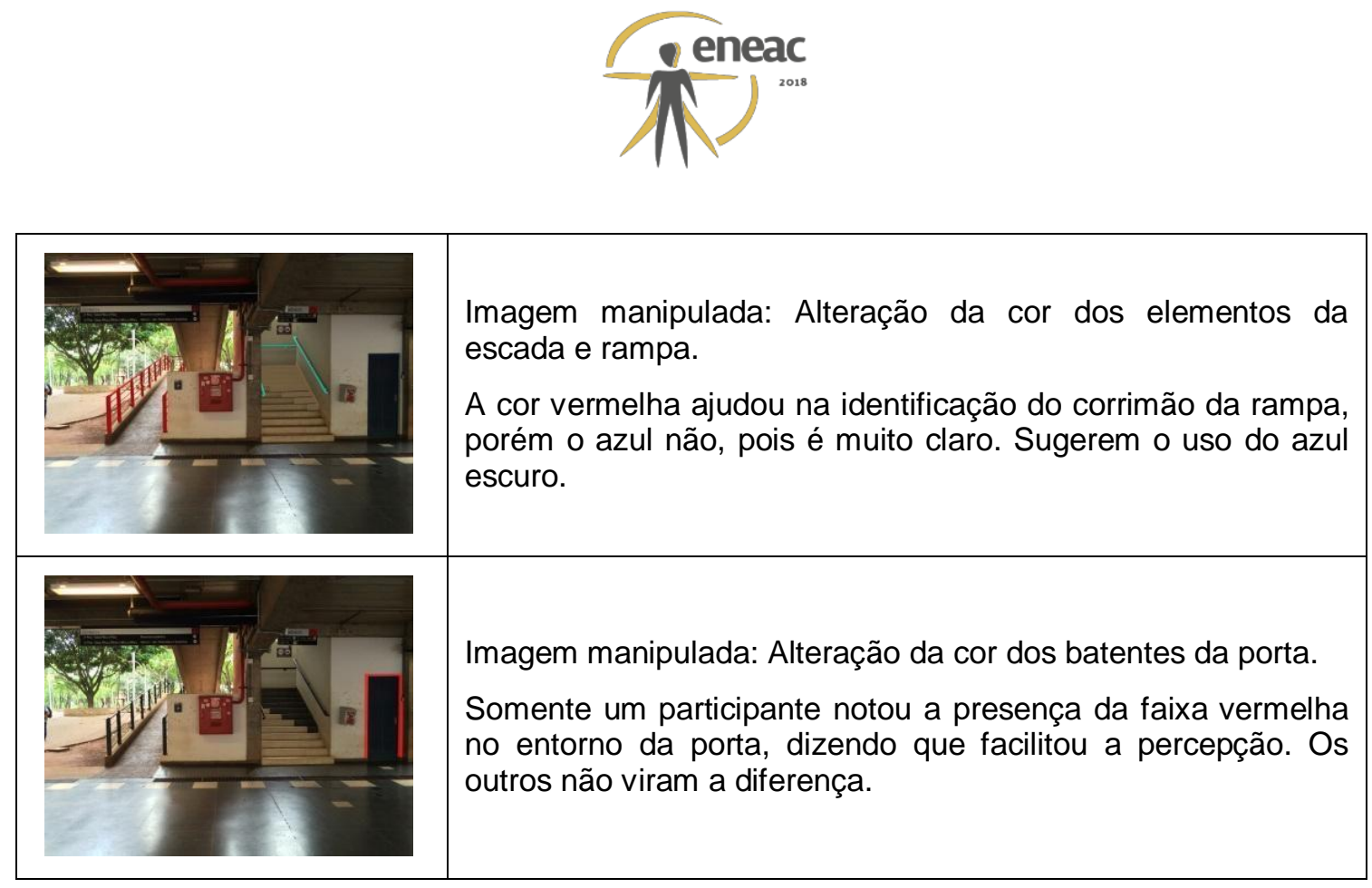

Fonte: elaborado pelos autores.

\section{DISCUSSÃO E CONCLUSÕES}

$\mathrm{Na}$ maioria das imagens originais os participantes não notaram a presença de todas as barreiras, indicando que as cores presentes são pouco contrastantes com o entorno, o que faz com que as barreiras sejam pouco perceptíveis. Por diversas vezes os participantes somente visualizaram elementos já na imagem alterada, quando já estavam com as novas cores, indicando a importância dos contrastes cromáticos.

$\mathrm{O}$ amarelo foi identificado como a cor mais eficiente quando se fala em contrastes nos elementos urbanos, sendo que por diversas vezes os tons de vermelho, rosa, azul claro e verde claro não melhoraram significativamente a percepção dos elementos, por estarem empregados em tons muito claros, segundo os participantes. Foi apontada a importância de se utilizar cores fortes, fluorescentes, em vez de cores claras.

Alguns pontos devem ser destacados, como a dificuldade na visualização das cores vermelho e azul, principalmente quando em tons mais claros; e a variação de percepção entre pessoas que dependem de diferentes níveis de luminosidade para enxergar cores, sendo que havia dois participantes nos extremos opostos: um que enxerga melhor com menos luminosidade e, inclusive, usa óculos de sol com frequência; e outro que enxerga somente com grande luminosidade. Estes aspectos tornam a avaliação menos efetiva, uma vez que cada pessoa tem um nível de percepção bastante único, gerado pela combinação de patologias e causas específicas. É importante também destacar a dificuldade na identificação de degraus de mesma cor e do início e fim de escadas, fator que foi consenso entre todos os participantes, que concordaram com a proposta de pintar faixas de cores contrastantes nas margens dos degraus e sugeriram a variação de cores de um degrau para outro.

Uma dificuldade observada na dinâmica foi o tamanho reduzido das imagens, que foram mostradas aos participantes através de um notebook. Uma alternativa seria a apresentação das imagens em tamanho maior, como em telas projetadas na parede. Os participantes citaram inúmeras vezes que em uma situação real provavelmente a mudança de cores nos elementos traria uma melhora significativa para a sua orientação no espaço.

Além disso, a quantidade de participantes (sete) foi pequena. Nota-se que para maior efetividade nos resultados da pesquisa o cenário ideal seria com um número maior de participantes, para uma avaliação mais ampla e abrangente; com separação dos 


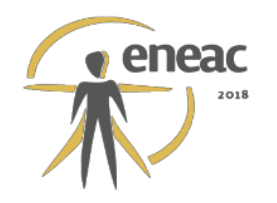

participantes em diferentes grupos de pessoas com níveis de percepção semelhantes (aqueles que enxergam com mais luminosidade, aqueles que têm melhor visão periférica, aqueles que têm visão embaçada, entre outros).

Os resultados da dinâmica realizada apontam que os contrastes cromáticos aplicados em elementos do mobiliário urbano podem ser eficientes no auxílio à orientabilidade de pessoas com baixa visão. Assim, para o propósito de avaliar se o uso das cores poderia ser um instrumento para a melhoria na mobilidade das pessoas com baixa visão, o trabalho foi efetivo, apontando que esta é uma alternativa a ser explorada, podendo no futuro gerar incontáveis benefícios às pessoas com deficiência visual, minimizando riscos no que concerne a sua mobilidade e gerando autonomia, fator primordial na vida das pessoas com deficiência.

\section{AGRADECIMENTOS}

Agradecimentos ao Centro Cultural Louis Braille de Campinas, que gentilmente permitiu a realização da dinâmica com seus frequentadores. Agradecimentos às pessoas com baixa visão que participaram da dinâmica, pois tiveram papel indispensável na obtenção dos resultados alcançados. Agradecimentos ao PIBIC/CNPq pelo fomento da pesquisa.

\section{REFERÊNCIAS BIBLIOGRÁFICAS}

Associação Brasileira de Normas Técnicas. NBR9050: Acessibilidade à edificações, mobiliário, espaços e equipamentos urbanos. 3a ed. Rio de Janeiro, 2015.

Associação Brasileira de Normas Técnicas. NBR9283: Mobiliário Urbano. 1a ed. Rio de Janeiro, 1986.

BINS ELY, Vera H. M.; DISCHINGER, Marta; PIARDI, Sonia M. D. G. Promovendo acessibilidade espacial nos edifícios públicos: Programa de Acessibilidade às Pessoas com Deficiência ou Mobilidade Reduzida nas Edificações de Uso Público. Florianópolis: MPSC, 2012.

Cartilha do Censo 2010, Pessoas com Deficiência (2012). Disponível em:

<http://www.pessoacomdeficiencia.gov.br/app/sites/default/files/publicacoes/cartilha-censo-2010pessoas-com-deficienciareduzido.pdfv> Acesso em: 10/04/2016.

CARVALHO, Keila Mirian M. Visão Subnormal: orientações ao professor do ensino regular, $3^{a}$ Edição. Campinas, SP, Editora da Unicamp, 2002.

GAMITO, M. M. O. A. Cor no Mobiliário Urbano - Um Factor de Inclusividade, Orientação e Identificação. Tese de Doutorado; Universidade Técnica de Lisboa; Lisboa, 2012.

GUIMARÃES, Luciano. A Cor como Informação: a construção biofísica, linguística e cultural da simbologia das cores. São Paulo: Annablume, 2000.

MONT'ALVÃO, Claudia, Projeto Cromático para Sistemas Informacionais do Ambiente Construído de EAs. In: MONT'ALVÃO, Claudia; VILLAROUCO, Vilma; Um novo olhar para o projeto - A ergonomia no ambiente construído: RANGEL, Márcia M. Vol 2. Recife: Editora UFPE, 2014.

NISHIMORI, Renato A. V. Ferramenta de acessibilidade para deficientes visuais em cores (2013). Disponível em <http://bcc.ime.usp.br/principal/tccs/2013/renato/monografia.pdf> Acesso em 11/04/2016.

VARELLA, Drauzio. Deficiência Visual (2012). Disponível em: $<$ http://drauziovarella.com.br/envelhecimento/deficiencia-visual/> Acesso em 10/04/2016. 